\title{
Emociones, semillas nativas y cambio climático: el movimiento de soberanía de las semillas en Chiapas, México
}

\section{Emotions, Native Seeds, and Climate Change: The Seed Sovereignty Movement in Chiapas, Mexico}

\author{
Carol Hernández RodríGuez \\ Departamento de Sociología, Universidad Estatal de Portland, Estados Unidos \\ Hugo Perales Rivera \\ El Colegio de la Frontera Sur, San Cristóbal de Las Casas, Chiapas, México \\ DANIEL JAFFEE \\ Departamento de Sociología, Universidad Estatal de Portland, Estados Unidos
}

\begin{abstract}
Resumen: ¿Qué papel juegan las emociones en la definición de marcos interpretativos que permiten a las comunidades responder acertadamente a los retos impuestos por el cambio climático? Este artículo explora empíricamente la cuestión desde la perspectiva de pequeñas comunidades campesinas en la región central de Chiapas, México. El estudio de caso muestra que los significados espirituales, culturales y materiales que las comunidades campesinas asignan a la milpa y sus semillas nativas, especialmente al maíz, convergen en un conjunto de emociones que permiten a sus miembros reconocer los riesgos de degradación ambiental y cambio climático y movilizarse políticamente en torno a la idea de soberanía de las semillas. Particularmente importante es el sistema informal de herencia de semillas de maíz de padres a hijos, el cual impone sobre las nuevas generaciones de campesinos la obligación moral y social de reproducir la milpa en orden de mantener vivo el espíritu de sus ancestros y deidades, contenido en las semillas, y preservar las condiciones ambientales necesarias para que las próximas generaciones puedan también vivir de la tierra y el maíz. El movimiento local de soberanía de las semillas exhorta y magnifica las emociones que subyacen a este compromiso moral al tiempo que enfatiza los riesgos para la reproducción futura de la milpa y las semillas impuestos por prácticas agrícolas (uso de agroquímicos, deforestación, cuasi-monocultivos)
\end{abstract}


que contribuyen a la degradación del medio ambiente. Tres agendas constituyen los principales ejes del movimiento: agroecología, conservación de la agrobiodiversidad y adaptación de la milpa al cambio climático.

Palabras Clave: maíz; milpa; sistemas campesinos de semillas; herencia de semillas; altar maya.

AвSTRACT: What role do emotions play in the creation of interpretive frameworks that allow communities to respond effectively to the challenges posed by climate change? This article explores this question empirically from the perspective of small indigenous peasant communities in the central region of Chiapas, Mexico. The study shows that the spiritual, cultural and material meanings that indigenous communities assign to the traditional milpa agroecosystem and to their native seeds, particularly maize, converge in a conjunction of emotions that enables these communities to recognize the risks posed by environmental degradation and climate change, and to mobilize politically around the frame of seed sovereignty. Particularly important is the informal system by which children inherit maize seed from their parents, which imposes on new generations the moral and social obligation of reproducing the milpa. This reproduction is necessary to keep alive the spirits of their ancestors and deities, which are thought to be embodied in the seeds, and to preserve the environmental conditions needed for future generations to live from the maize and the land. The regional social movement around seed sovereignty embraces and amplifies the emotions that underlie this moral and cultural commitment, at the same time as it emphasizes the risks posed by conventional agricultural practices (agrochemical use, deforestation, and quasi-monoculture) and environmental deterioration to the sustenance of the milpa and seeds. Three key foci comprise the agenda of this movement: agroecology, agrobiodiversity conservation, and adaptation of the milpa to climate change.

KeYwords: Maize; milpa; peasant seed systems; seed inheritance; Maya altar.

RECEPCIÓN: 30 de septiembre de 2019.

ACEPTACIÓN: 10 de diciembre de 2019.

Dol: https://doi.org/10.19130/iifl.ecm.2020.56.2.0009

\section{Introducción: cambio climático, agricultura campesina y maíz nativo}

El cambio climático es el fenómeno medioambiental más significativo de nuestro tiempo y la comunidad científica espera efectos catastróficos para el planeta y la sociedad, entre los que destacan la pérdida de biodiversidad y una caída pronunciada en la productividad agrícola, lo cual afectaría los sistemas agroalimentarios del mundo entero (Cline, 2008; Nelson et al., 2009; IPCC, 2019; FAO, 2019). Se prevé que los impactos negativos del cambio climático en biodiversidad y agricultura serán mucho mayores en los países en desarrollo, debido, en gran medida, a que 
se localizan en áreas geográficas más cercanas al ecuador, lo cual los expone a un incremento de temperaturas cálidas que puede exceder la tolerancia de cultivos, plantas y animales (Cline, 2008). Los países subdesarrollados también registran menor capacidad técnica e institucional para implementar reformas estructurales enfocadas en mitigar y adaptarse al cambio climático (IPCC, 2019). En el caso de México, que de acuerdo con el CCPI (Climate Change Performance Index, 2019) se ubica entre los países con desempeño bajo en la implementación de medidas de mitigación, se prevé una pérdida potencial en la productividad agrícola de entre 25 y 35\% para el año 2080 (Cline, 2008). Este pronóstico ubicaría a nuestro país dentro de las naciones del mundo más afectadas por el cambio climático (Cline, 2008; IPCC, 2019). ${ }^{1}$

A pesar de que los campesinos de subsistencia en los países del sur contribuyen poco a las emisiones de carbón a la atmósfera, suelen ser uno de los sectores más directamente afectados por las variaciones climáticas y sus efectos en el medio ambiente. Esto se debe, en parte, a que su agricultura suele depender enteramente de los ciclos de precipitación pluvial y de la calidad de los recursos naturales como la tierra, el agua y las semillas nativas (Morton, 2007; Mercer, Perales y Wainwright, 2012; Vermeulen, 2014). Las amenazas impuestas por el cambio climático a la agricultura de subsistencia constituyen a su vez un riesgo potencial para la conservación de la biodiversidad —ubicada abrumadoramente en el sury, por lo tanto, para la evolución y adaptación de la agricultura mundial al cambio climático (Vincent et al., 2013; Altieri y Nicholls, 2013; Coomes et al., 2015).

En el caso del maíz, uno de los cuatro cultivos más importantes del mundo y el más importante en México, el cambio climático constituye una amenaza no sólo para esta nación sino para el mundo entero puesto que México es el centro de origen y diversidad de este cultivo (Jones y Thornton, 2003; Mercer y Perales, 2010; Bellon, Hodson y Hellin, 2011; Li et al., 2011; Hellin, Bellon y Hearne, 2014; Msowoya et al., 2016). Particularmente, para el maíz nativo se debe tomar en cuenta que ha estado presente en la vida de los pueblos mesoamericanos por casi 9,000 años y ha sido un componente central de su dieta por casi tres milenios (Wilkes, 2004; Buckler y Stevens, 2005; Ford y Nigh, 2009; Piperno et al., 2009). En el proceso de reproducir el maíz nativo las comunidades campesinas han hecho posible la evolución de su cultivo, permitiendo su adaptación paulatina a las variaciones climáticas. La información genética contenida en los maíces nativos podría ser estratégica para el desarrollo futuro de variedades de maíz, tanto nativas como industriales, capaces de adaptarse a los escenarios previstos de cambio climático en diferentes partes del mundo (Mercer y Perales, 2010; Bellon, Hodson y Hellin, 2011; Hellin, Bellon y Hearne, 2014; Bellon et al., 2017).

\footnotetext{
${ }^{1}$ Para contextualizar estos datos, es útil mencionar que se calcula para los países industriales una pérdida potencial de productividad agrícola de $6 \%$ en promedio, mientras que para los países subdesarrollados este porcentaje se incrementa entre 9 y $21 \%$, con los países más vulnerables como Senegal y Sudán, en África, registrando una pérdida de productividad de hasta 50 por ciento (Cline, 2008).
} 
Más allá del valor genético del maíz nativo para la agricultura mexicana y mundial, es importante destacar los significados culturales, espirituales y materiales que este cultivo tiene para la población de México. No es insignificante que uno de los movimientos sociales de carácter nacional más dinámicos que han surgido en el país en las últimas décadas sea el movimiento por la defensa del maíz en el contexto del TLCAN. $^{2}$ Este movimiento, cuyas expresiones más conocidas son las campañas de soberanía alimentaria y anti-transgénicos Sin Maíz No Hay País y Semillas Madre en Resistencia desde las Tierras de Chiapas (una iniciativa zapatista), ha sido capaz de integrar en una misma agenda política un rechazo a la liberalización del sector del maíz mexicano, la introducción de maíz genéticamente modificado y la imposición de derechos de propiedad intelectual sobre las semillas, así como una reivindicación del valor de la agricultura campesina, la importancia estratégica del maíz nativo y su carácter como bien común. Sin embargo, ha sido muy reciente que algunos sectores del movimiento, particularmente los campesinos y científicos, han comenzado a reconocer el cambio climático y la degradación ambiental como algunos de los riesgos más importantes para la preservación del maíz nativo (Hernández, 2018).

¿Cómo perciben, experimentan y responden las comunidades campesinas a los fenómenos de cambio climático y degradación medioambiental? ¿Qué papel juegan las emociones en la definición de marcos interpretativos útiles que permiten a las comunidades responder acertadamente a los retos impuestos por tales fenómenos? El presente artículo explora empíricamente estas preguntas por medio de un estudio etnográfico en la región central de Chiapas, en el suroeste de México, un área predominantemente indígena donde la agricultura de subsistencia basada en semillas nativas aún constituye la fuente central de alimentos para los hogares. Enfocado en los valores espirituales, culturales y materiales que las comunidades asignan a la milpa y sus semillas nativas, este trabajo analiza la forma en que estos valores convergen y se materializan en un conjunto de emociones individuales y colectivas que dan vida al movimiento local de soberanía de las semillas, del cual se derivan los proyectos comunitarios de mitigación de degradación ambiental y adaptación de la agricultura campesina al cambio climático.

\section{Emociones y movimientos sociales en el contexto de cambio climático}

Uno de los principales objetivos de la literatura sobre movimientos sociales es entender las motivaciones que guían a las personas a unirse a uno de éstos y, más aún, lo que les permite mantenerse comprometidos con dicho movimiento por un periodo significativo (Della Porta y Diani, 2009; Goodwin y Jasper, 2015). En los últimos años, los estudiosos han enfatizado aún más la centralidad de las emociones y los sentimientos de los individuos y comunidades en la conforma-

\footnotetext{
${ }^{2}$ Tratado de Libre Comercio de América del Norte, desde 2019 Tratado entre México, Estados Unidos y Canadá.
} 
ción y devenir de los movimientos sociales (Norgaard, 2006; 2011; Jasper, 2018; Jasper y Polleta, 2018). De acuerdo con Norgaard (2011) las emociones y sentimientos influyen en los valores morales sobre los que se establecen los marcos interpretativos de los movimientos, en la definición de sus objetivos e incluso en los esquemas motivacionales que atraen a nuevos participantes y unen a sus miembros. Asimismo, las emociones y los sentimientos, incluyendo angustia, impotencia, enojo, apatía, y/o desdén también determinan la falta de acción por parte de los individuos y su incapacidad de formar o unirse a un movimiento (ver también Zerubavel, 2002; Goodwin y Jasper, 2015).

Las respuestas sociales al cambio climático ofrecen un caso paradigmático para analizar cómo las emociones interactúan y determinan la percepción del riesgo y las acciones de individuos y colectivos en múltiples direcciones (Norgaard, 2006; 2011; Brechin, 2008; Roeser, 2012; Della Porta y Parks, 2014; Dunlap y Brulle, 2015; Weber, 2015; McAdam, 2017). Una de las grandes preguntas que han surgido en esta área de estudio es: ¿qué motiva o inhibe a algunas personas y comunidades a reconocer el cambio climático como un problema de primer orden $\mathrm{y}$, como consecuencia, a emprender acciones concretas que ayuden a mitigar sus causas y efectos? Mientras múltiples estudios abordan esta pregunta en los países del norte, particularmente en contextos urbanos (Norgaard, 2006; 2011; Brechin, 2008; Brulle, 2013; McCright and Dunlap, 2016; McAdam, 2017), este artículo busca contribuir empíricamente al análisis de los factores que impulsan a individuos y comunidades rurales en el sur de México a tomar medidas a favor de la mitigación de cambio climático, destacando las emociones. Este es uno de los primeros estudios en analizar el papel que juegan las emociones en la percepción del cambio climático en los países del sur y, más específicamente, entre comunidades rurales.

\section{Área de estudio y métodos}

El área de estudio abarca parcialmente seis municipios (San Andrés, San Juan Cancuc, Tenejapa, Tumbalá, Teopisca y Venustiano Carranza) localizados en tres regiones de la parte central de Chiapas (Los Llanos, Los Altos y Norte-Tulijá). Durante el estudio de campo, el cual tuvo lugar entre agosto de 2015 y marzo de 2016, se recolectó información de 51 comunidades, de las cuales tres son de población predominantemente mestiza (municipios de Teopisca y Venustiano Carranza) y 47 de población mayoritariamente indígena. Entre las comunidades indígenas, 16 son de origen tseltal (Cancuc y Tenejapa), 19 de origen tsotsil (San Andrés) y 12 de origen ch'ol (Tumbalá). El estudio integra 25 comunidades no zapatistas y 26 comunidades afiliadas al Ejército Zapatista de Liberación Nacional (EZLN). La diversidad étnica, linguística y política, así como la distribución geográfica de las comunidades que participan en este estudio, es una representación a pequeña escala de la región central de Chiapas, por lo cual se usará esta denominación territorial a través del artículo para referirse al área de estudio. 
A pesar de estas distinciones, todas las comunidades integradas en el estudio colaboran cercanamente con la organización local Desarrollo Económico y Social para los Mexicanos Indígenas (en adelante, DESMI) en temas de agroecología y de soberanía alimentaria y de las semillas. ${ }^{3}$ DESMI fungió como vínculo central entre los investigadores y las comunidades que integran este estudio.

Esta investigación etnográfica incorpora tres componentes centrales: (1) entrevistas semi-estructuradas con actores clave; (2) observación participativa y no participativa, y (3) análisis de documentos. En total se realizaron 63 entrevistas, esto incluye 39 con miembros de comunidades zapatistas y no zapatistas; 13 con miembros de organizaciones locales y activistas; seis con miembros activos y retirados por avanzada edad de la pastoral de la diócesis de San Cristóbal, y cinco entrevistas con académicos de universidades y centros de investigación públicos en San Cristóbal: El Colegio de la Frontera Sur (Ecosur) la Universidad Autónoma de Chapingo y el Centro de Estudios para el Cambio en el Campo Mexicano (СECCAM). Cuatro temas intrínsecamente vinculados con la reproducción de las semillas nativas destacan como centrales en las entrevistas: significados espirituales y culturales, seguridad alimentaria, degradación medioambiental y cambio climático. Por cuestiones de confidencialidad, y en concordancia con los términos del Institutional Review Board (IRB) de Portland State University, Oregon, Estados Unidos, para investigación con sujetos sociales, se usan pseudónimos para identificar a los entrevistados, así como a sus organizaciones y comunidades. Las citas presentadas en este artículo provienen de las entrevistas semi-estructuradas desarrolladas para esta investigación.

\section{El estudio en contexto: el movimiento local de soberanía de semillas}

El movimiento local de soberanía de semillas se originó formalmente en 2002, cuando el EzLn lanzó su campaña Semillas Madre en Resistencia desde las Tierras de Chiapas. Ésta surgió después de que un grupo de investigadores de la Universidad de California-Berkeley encontraron trazos transgénicos en maíz nativo en el estado de Oaxaca (Quist y Chapela, 2001). En colaboración con la organización no gubernamental (ONG) estadounidense Schools for Chiapas, el EzLn llevó a cabo alrededor de 1,000 pruebas para detectar trazos transgénicos en diferentes variedades de maíz nativo cultivado en las cinco regiones que integran el territorio zapatista (Brown, 2013; Schools for Chiapas, 2017). Después de corroborar que el maíz local era "aún natural" y "no está enfermo de la avaricia de las corporaciones" (Brown, 2013), el Ezln declaró el territorio zapatista como una zona libre de transgénicos y, en un intento por generar una voz global en contra del maíz genéticamente modificado, donó más de 20 variedades locales de maíz a diferentes

\footnotetext{
${ }^{3}$ Creada en 1969 por el arzobispo Samuel Ruiz de la diócesis de San Cristóbal, DESMı es una de las organizaciones más consolidadas y prestigiadas en la región. Hoy en día trabaja con más de 200 comunidades zapatistas y es una de las pocas organizaciones que también colabora con comunidades no zapatistas.
} 
colectivos en el mundo (Brown, 2013; Brandt, 2014). Desde entonces, Semillas Madre en Resistencia ha trabajado en difundir información sobre los organismos genéticamente modificados (oGms) entre las comunidades campesinas de Chiapas, incluyendo comunidades no zapatistas. Esta campaña también continúa hoy en día promoviendo la reproducción del maíz zapatista en parcelas alrededor del mundo (Brown, 2013; Brandt, 2014; Schools for Chiapas, 2017).

Semillas Madre en Resistencia fue el inicio político de un proyecto estructural de mayor alcance enfocado en preservar el maíz nativo, implementar estrategias para su adaptación al cambio climático y reforzar los significados culturales, espirituales y materiales que éste tiene para las comunidades campesinas mayas. Este proyecto vino a fortalecer el trabajo de soberanía alimentaria que el movimiento zapatista ha desarrollado entre sus comunidades desde décadas atrás, y que se formalizó en 2003 con la adopción del modelo agroecológico como el nuevo paradigma de agricultura campesina en territorio zapatista. Ese mismo año se crearon los comités regionales y comunitarios de agroecología, que tienen entre sus principales objetivos revertir la dependencia generalizada de los agroquímicos y fomentar la transición de las comunidades hacia un modelo de agricultura más sustentable basado en métodos de producción orgánicos y agroecológicos (ezln, 2003; Hernández, 2018; Hernández, Perales y Jaffee, en prensa).

Como parte de este proyecto agroecológico, la agenda zapatista de soberanía de semillas incluye el desarrollo a nivel comunitario de inventarios de semillas nativas, la creación de bancos de semillas (tanto casas de semillas como "bancos vivos" de semillas o parcelas de cultivo), la promoción de la diversificación del maíz en la milpa, la creación de parcelas experimentales para adaptar el maíz al cambio climático y el desarrollo de una agenda política enfocada en redefinir las semillas nativas como un bien común en oposición a los derechos de propiedad intelectual sobre el germoplasma (ver, para un análisis detallado del desarrollo de estos proyectos, incluyendo sus limitaciones, Hernández, 2018; Hernández, Perales y Jaffee, en prensa).

En la última década, estos proyectos, particularmente aquellos enfocados en las semillas, han comenzado a ser adoptados por algunas comunidades no zapatistas. Tal desarrollo se debe en gran media al trabajo de la Pastoral de la Madre Tierra de la diócesis de San Cristóbal, que en 2014 organizó el Congreso Diocesano de la Madre Tierra y en Defensa del Territorio (Diócesis, 2014; Lerna, 2015). En dicho congreso, las comunidades y organizaciones participantes, incluyendo DESMI, asumieron el compromiso de trabajar en el desarrollo de iniciativas en dos frentes: implementar medidas para mitigar el deterioro ambiental en las comunidades y organizarse políticamente para defender sus territorios y recursos naturales frente al capital extranjero y los megaproyectos (carreteras, represas, el tren maya, etcétera) propuestos por los gobiernos estatal y federal. ${ }^{4}$ El trabajo de

\footnotetext{
${ }^{4}$ DESMI se comprometió a organizar el proyecto "Guardianes de la Madre Tierra y las Semillas" con las 25 comunidades no zapatistas integradas en este estudio.
} 
concientización política enfocado en el medio ambiente y los recursos naturales de la Pastoral de la Madre Tierra ha sido ampliamente reforzado y legitimado por la publicación en 2015 de la Carta Encíclica Laudato Si' Sobre el Cuidado de la Casa Común por el papa Francisco. Las siguientes secciones nos ayudan a comprender mejor por qué la idea de soberanía de semillas, y más particularmente la preservación del maíz nativo, se ha constituido en uno de los principales motores, tanto en comunidades zapatistas como no zapatistas, de este movimiento político por la preservación y defensa del territorio y los recursos naturales.

\section{"Nosotros somos el pueblo del maíz": los significados espirituales, culturales y materiales de las semillas nativas}

La importancia que las semillas nativas, y particularmente el maíz, tienen para las comunidades campesinas de la región de estudio hace de ellas un referente esencial cuando las personas intentan explicar quiénes son y cuáles son sus raíces y creencias. El movimiento de soberanía de las semillas que está tomando forma entre estas comunidades da cohesión a los múltiples significados que las semillas nativas y la milpa tienen para sus miembros. Como veremos, lejos de estar acotada al valor material de las semillas, la idea de soberanía de las semillas también nos habla sobre el origen y reproducción de dichas comunidades, así como de su propia conceptualización como hombres del maíz que pertenecen a la tierra.

\section{Semillas sagradas: la teología maya y la ceremonia del altar maya}

La ceremonia del altar maya es actualmente uno de los rituales espirituales más populares y practicados por las comunidades indígenas en toda la región de estudio. De acuerdo con Xaw, un practicante ${ }^{5}$ tseltal no zapatista de la teología india, el altar maya es una ceremonia sincrética particularmente importante en la región porque combina, como ningún otro ritual, prácticas y simbolismos tradicionales con significados y objetivos políticos contemporáneos. Los orígenes de esta ceremonia, de acuerdo con su narración, son desconocidos, pero se considera que es un rito precolombino que nació en las tierras mayas de Guatemala. El altar maya adquirió renovada relevancia a finales de la década de 1990 con el desarrollo de la teología india. ${ }^{6}$ Jxun, un practicante tseltal zapatista, comenta:

\footnotetext{
${ }^{5}$ Practicante en este artículo se refiere a la persona que profesa y practica una religión o una filosofía espiritual, en este contexto, la religión católica y/o la teología india o maya. En muchos casos, los participantes en este estudio son practicantes de ambas, lo cual refleja el sincretismo entre la religión católica y las creencias espirituales autóctonas en la región. Más específicamente, cuando hablamos de practicantes de la teología maya en esta sección, nos referimos a aquellos que participan activamente en la reproducción de ceremonias y rituales espirituales, ya sea como líderes espirituales o como aprendices, como en el caso de Jxun y Xaw.

${ }^{6}$ La teología india o maya es una rama autóctona de la teología de la liberación y de la doctrina
} 
"lo que hoy en día se conoce como el altar maya, al menos en la diócesis [de San Cristóbal], es un ritual renovado y sofisticado que refleja la re-significación política e intelectual de lo que significa ser indígena en Chiapas”. Tres elementos importantes convergen hoy en esta ceremonia, de acuerdo con Xaw: "las prácticas y creencias tradicionales de los pueblos indígenas, las cuales siempre han estado ahí; la lucha zapatista por la autonomía indígena con todas sus ideas sobre los derechos indígenas, la justicia, la libertad y una vida digna, y el compromiso diocesano de acompañar a los pueblos indígenas en su caminar, un compromiso que viene de jtatik Samuel (obispo Samuel Ruiz) y la adopción por parte de la diócesis de la 'opción por los pobres' (una doctrina de la teología de la liberación)".

Vale la pena describir aquí la ceremonia del altar maya ${ }^{8}$ debido al papel central que desempeñan las semillas nativas, las cuales, de acuerdo con los campesinos, encarnan el espíritu — ch'ulel, en tseltal y tsotsil- de sus ancestros y deidades. ${ }^{9}$ La descripción del altar maya nos ayuda a ilustrar algunos de los significados colectivos que las comunidades asignan a sus semillas nativas. Como discutimos más adelante, estos significados espirituales y culturales son elementos esenciales que dan vitalidad a las prácticas históricas de herencia e intercambio de semillas al interior de las comunidades y con ellas a la evolución de los sistemas de semillas nativas y la biodiversidad.

El objetivo de la ceremonia del altar maya es entablar un diálogo con los ancestros de las comunidades para pedirles consejo y acompañamiento cuando las personas tienen que tomar decisiones importantes o resolver situaciones difíciles. La ceremonia también ofrece una oportunidad para pedir perdón a los ancestros por acciones incorrectas que han causado daño a la comunidad. ${ }^{10}$ Es importante notar que cuando los individuos se refieren a sus ancestros, éstos incluyen tanto a los ancestros de sus comunidades como a los ancestros colectivos de los pueblos mayas. Esta práctica refleja el grado en que las comunidades mayas se perciben a

\footnotetext{
"preferencia por los pobres", como se le denomina en Chiapas. La teología india nació en la diócesis de San Cristóbal de la confluencia entre el catolicismo y la espiritualidad maya, y adquirió relevancia como una fuerza política a principios de los años de 1990. Este desarrollo fue un resultado indirecto de la institucionalización de un diaconado indígena en 1973, el cual fue promovido por el arzobispo Samuel Ruiz; pero también refleja la creciente importancia de las tradiciones, filosofías y prácticas indígenas en un contexto regional marcado por la lucha zapatista por la autonomía de los pueblos indígenas. Los miembros de la teología india forman parte de la diócesis de San Cristóbal, aunque existen muchos practicantes que no mantienen un cargo oficial en la iglesia católica. También existe un creciente grupo de intelectuales indígenas, como Jxun y Xaw, quienes crecientemente contribuyen a la documentación, estudio, interpretación y reproducción de las prácticas tradicionales de las comunidades indígenas (Jxun y Xaw, comunicación personal).

${ }^{7}$ Jxun y Xaw, entrevista colectiva, febrero de 2016.

${ }^{8}$ La descripción del altar maya que se presenta en este artículo está basada en múltiples ceremonias que se presenciaron durante la estancia de trabajo de campo en Chiapas. Las interpretaciones de los objetivos de la ceremonia y de los elementos que constituyen el altar provienen de varios de los participantes y de la entrevista colectiva con Jxun y Xaw.

${ }^{9}$ Ver D’Alessandro y González, 2017: 280-291 para una reseña de la literatura sobre los significados referentes al altar maya en la región tseltal de Los Altos de Chiapas.

${ }^{10} \mathrm{Jxun}$, entrevista, febrero de 2016.
} 
sí mismas como miembros de una comunidad más grande y antigua que trasciende la historia de familias individuales, así como los límites étnico-lingüísticos y geográficos de comunidades individuales. Este es el motivo por el cual miembros de diferentes comunidades pueden participar en una misma ceremonia.

La ceremonia es dirigida por líderes espirituales que pueden ser diáconos de la diócesis, miembros de los consejos de ancianos de las comunidades o practicantes de la teología india que se están entrenando para convertirse en líderes espirituales, como es el caso de Jxun y Xaw. La ceremonia comienza con la preparación del altar maya. Existen muchas versiones de altar, pero la más popular en esta región consiste en un círculo de aproximadamente tres metros de diámetro trazado en el suelo. El círculo simboliza el cosmos, la tierra y la milpa. El círculo se cubre con hojas de pino y se divide en cuartos, cada uno representa una dirección cardinal: este, oeste, norte y sur. Los cuatro puntos cardinales también denotan a los cuatro guardianes, los cuatro vientos y los cuatro pilares de la humanidad (Figura1).

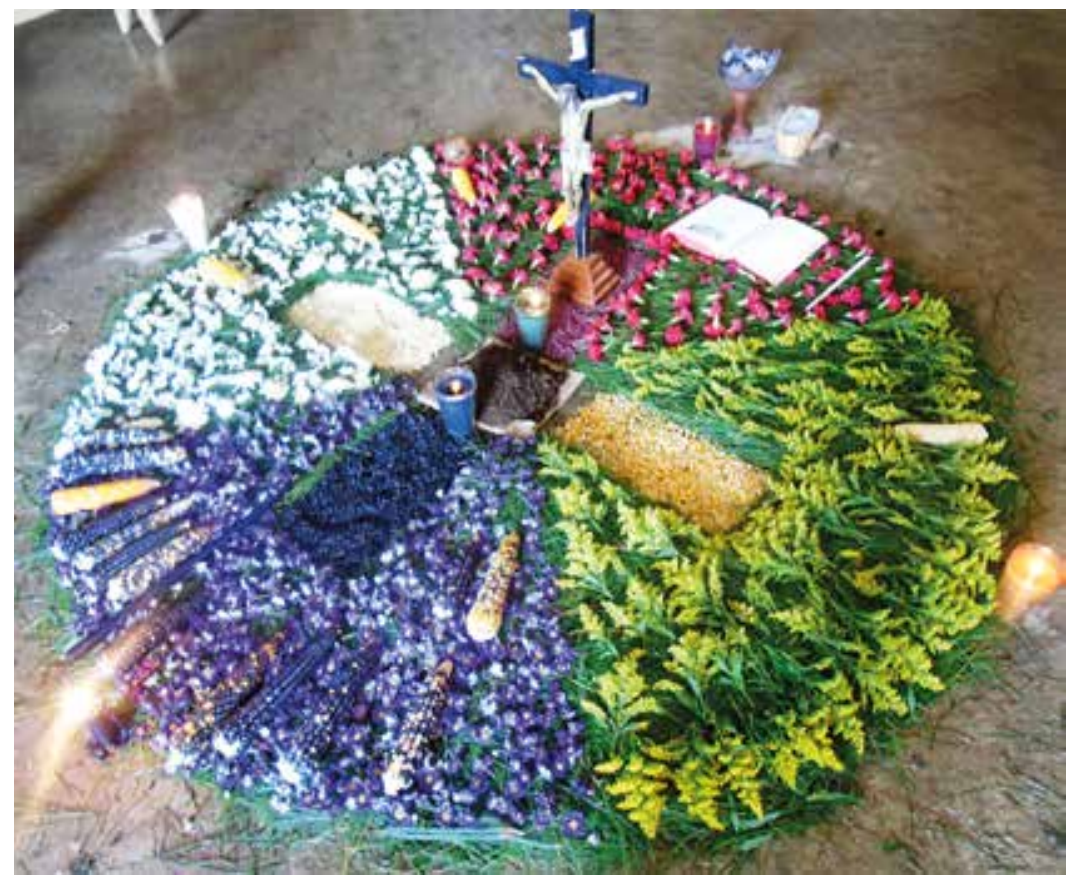

Figura 1. Ofrenda del altar maya. El altar representa el universo, la Madre Tierra y la milpa (Fotografía de Carol Hernández).

Para cada punto cardinal se asigna un color: rojo el este, negro el oeste, blanco el norte y amarillo el sur. Cada cuarto se cubre con flores y semillas de maíz nativo del mismo color. El color rojo en el este representa el Sol, el nacimiento de la humanidad, la posibilidad de germinación, el poder del fuego y la intensi- 
dad de la sangre. El negro en el oeste simboliza la noche, cuando el sol descansa en el inframundo y viaja a través de las energías obscuras de la muerte, pero también a través de las raíces de la vida. El inframundo es el vientre donde la humanidad es recreada. Es el espacio donde la transformación ocurre y donde los humanos encuentran sus propios espíritus. El maíz negro simboliza también el color del cabello de los pueblos mayas. El norte, representado por el color blanco, es el lugar de donde los ancestros de estas comunidades provienen. Es la dimensión en la que habitan los espíritus colectivos de las comunidades. Heladas, sequías, tormentas, enfermedades y humillación se originan en el norte. Pero el color blanco también representa las semillas germinadas y los huesos originales de la humanidad. El sur, identificado por el color amarillo, es la casa cálida de todas las semillas, la fuente de vida de cada ser vivo. Es en el sur donde los guardianes de las semillas viven. El maíz amarillo también representa feminidad, fertilidad y es el color de la piel de los pueblos mayas. Al centro se localiza un pequeño montículo de tierra, representando a la Madre Tierra.

Atravesando el altar se encuentra la línea este-oeste, la cual recrea el camino de las deidades. La línea norte-sur representa el camino de la humanidad. El centro, donde los dos caminos se intersectan con la Madre Tierra, es donde los humanos se encuentran con las deidades y este encuentro simboliza el ideal del Lekil Kuxlejal-Ich'el ta muk', un término tseltal y tsotsil que se refiere al proceso de construir una vida digna para vivir con justicia y armonía (ver López, 2013 para un análisis amplio del concepto). Este es un término relativamente nuevo que ha adquirido considerable relevancia entre las comunidades indígenas desde el levantamiento zapatista de 1994.

Alrededor del círculo se ordenan múltiples anillos concéntricos formados con velas que proveen la luz para transitar de la dimensión material a la espiritual. También se coloca copal en la ofrenda, cuyo humo representa la esencia de los espíritus y su inhalación permite a las personas ser encarnadas por ellos. Cuando un diácono dirige la ceremonia, o cuando ésta tiene lugar en una parroquia, una imagen de un Cristo crucificado y una biblia abierta se ponen en el altar. Esto simboliza la confluencia del catolicismo con la espiritualidad maya, la cual dio vida a la teología india en los años de 1990 (ver nota 11).

De acuerdo con Jxun, quien ha enfocado su trabajo al estudio e interpretación de las filosofías y prácticas espirituales indígenas, estos rituales y las creencias que les dan vida no están fijos en el pasado. Por el contrario, están vivos y fluyen constantemente, y son "usados y entendidos", en palabras de Jxun, de acuerdo con las necesidades diarias de las comunidades. "La teología maya está de moda en estos días", dice riendo, "porque ésta ayuda a las comunidades a interpretar y explicar su propia realidad como pueblos indígenas". ${ }^{11}$

A continuación, se describe un pequeño fragmento de la ceremonia que tuvo lugar en la parroquia de San Andrés en octubre de 2015 en el marco de un taller

${ }^{11}$ Jxun y Wax, entrevista colectiva, febrero 2016. 
de soberanía de las semillas y agroecología (Figura 2). Al taller asistieron 136 representantes (dos por comunidad) de las nueve regiones que integra la parroquia, todos de origen tsotsil, además de las monjas responsables de la parroquia, tres representantes de DESMI y la primera autora. La narración ejemplifica los usos políticos de la ceremonia y, en este caso en particular, cómo a través de la espiritualidad, las comunidades discuten sobre sus prácticas agrícolas y la preservación de la Madre Tierra.

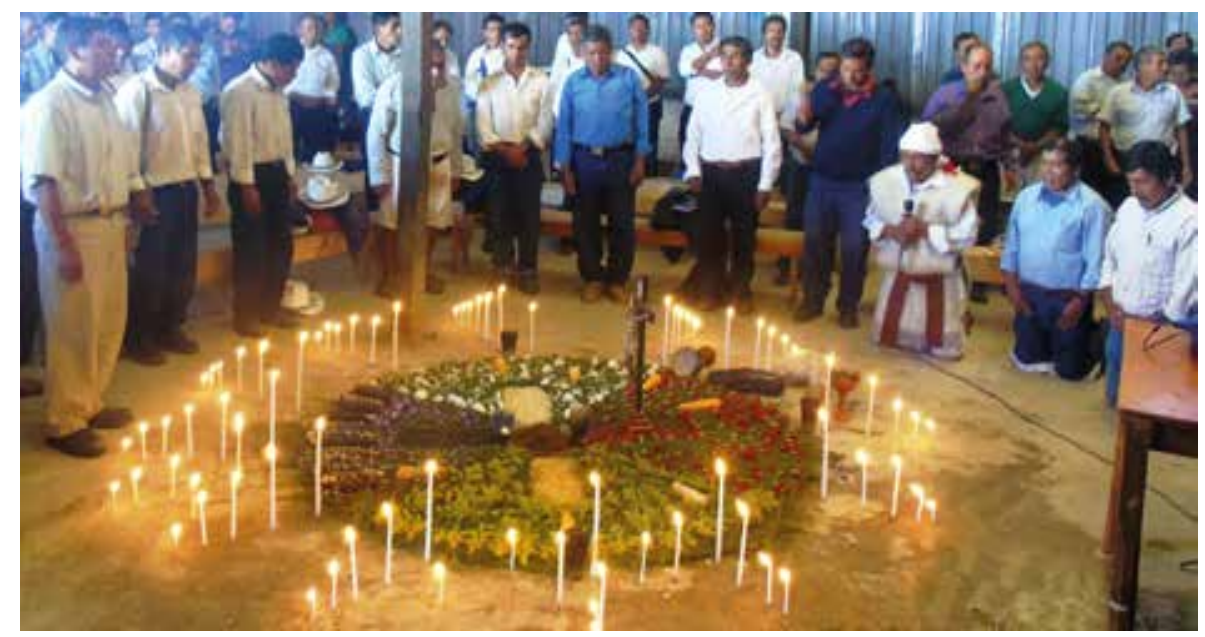

Figura 2. La ceremonia del altar maya. Las semillas nativas encarnan el espíritu o ch'ulel de los ancestros y deidades de las comunidades (Fotografía de Carol Hernández).

Después de que los líderes espirituales encargados de la ceremonia encienden el incienso y las 68 velas alrededor del altar, una por cada comunidad presente, un grupo de música tradicional tsotsil comienza a tocar las sonajas y el líder espiritual de mayor edad se hinca en el suelo e inicia su oración con un susurro. Todos los presentes se silencian de inmediato. Manuel, uno de los traductores del tsotsil al español, traduce la ceremonia para la primera autora y comenta que el guía está invitando a todos los participantes a abrir sus corazones e iniciar un diálogo con sus ancestros y con la Madre Tierra. De un momento a otro, el cuarto se llena de murmullos. Cada individuo comienza su propio diálogo, a su propio ritmo, y el sonido de las sonajas se intensifica. A pesar de la confluencia de sonidos y oraciones, la voz del guía sobresale a través del micrófono:

Hermanos y hermanas, necesitamos reconocer que no estamos viviendo en armonía con lo que nuestros ancestros nos enseñaron. Nosotros somos pobres y estamos desesperados, nuestros corazones están cerrados debido a tantas dificultades... No estamos cuidando a la Madre Tierra ni a nuestras comunidades. Nuestras tierras están exhaustas; ya no nos dan suficiente comida. Nuestros ríos están contaminados y por todos lados encontramos basura. Nuestros cuerpos están marcados por la en- 
fermedad y los más jóvenes sufren porque no estamos comiendo adecuadamente... Sabemos que no es fácil, y esa es la razón por la que pedimos el acompañamiento de nuestros ancestros. Tenemos que ser humildes y preguntar por su perdón y guía. Nuestros ancestros sabían cómo vivir como pueblos mayas. Debemos de estar avergonzados porque perdimos esa visión. Pero hoy estamos aquí para encontrar nuestro camino, el camino de nuestros ancestros. ${ }^{12}$

La oración del diácono es seguida por una intervención por parte de Margarita, una de las dos monjas a cargo de la parroquia, y quien organizó este taller de soberanía de las semillas; en español se dirige a la audiencia:

Como ustedes saben, el papa Francisco, en su encíclica, nos ha conminado urgentemente a reflexionar sobre nuestras responsabilidades y sobre cómo podemos cuidar nuestra casa común, la Madre Tierra. Pedir perdón es importante, pero no es suficiente. Tenemos que cambiar y hacer las cosas de manera diferente. Tenemos que pensar en soluciones. Eso es parte también de la encíclica... La Madre Tierra es nuestra casa y nosotros somos responsables de ella. Sin la naturaleza, sin nuestras tierras, no somos nada. Todos venimos de la tierra, de las semillas que crecen de la tierra. Todos tenemos el mismo origen. No podemos continuar destruyendo nuestra fuente de vida, tenemos que pensar también en los que vienen detrás de nosotros. Tenemos que pensar con claridad sobre las consecuencias de nuestras acciones. ¿El uso de químicos nos ayuda a preservar nuestras milpas, nuestros ríos, nuestras semillas, la salud de nuestras comunidades?... Nosotros, como parte del ministerio, tenemos la responsabilidad de reflexionar sobre nuestros problemas y encontrar soluciones para nuestras comunidades. ${ }^{13}$

\section{Sistemas campesinos de semillas: herencia, intercambio y reproducción de las semillas}

Como otros pocos elementos culturales, los sistemas de semillas nativas representan la esencia de las comunidades campesinas en la región de estudio y, al menos metafóricamente, recuentan los orígenes e historia de familias y comunidades enteras. Los sistemas locales de semillas hablan de la evolución de su agrobiodiversidad, prácticas agrícolas, dietas y creencias culturales y espirituales.

Reforzando estos elementos se encuentran las prácticas de herencia, intercambio y reproducción de semillas que prevalecen en todas las comunidades campesinas de la región de estudio, así como en otras comunidades campesinas de Chiapas (ver Sotelo, 2017). Como lo muestra la ceremonia del altar maya, para las comunidades indígenas las semillas nativas encarnan el espíritu o ch'ulel de sus ancestros (ver Estrada, 2009, para un análisis sobre la relación entre naturaleza, cultura e identidad entre las comunidades mayas contemporáneas). De acuerdo

12 Grabación, oración en un taller de soberanía de semillas, San Andrés, octubre de 2015.

${ }^{13}$ Grabación, discurso en un taller de soberanía de semillas, San Andrés, octubre de 2015. 
con Alux, un hombre tseltal de 57 años no zapatista de Cancuc, cada generación es responsable de mantener vivos a los ancestros de sus comunidades por medio de la reproducción de las semillas nativas heredadas a través del ciclo agrícola. Esto se logra por medio de la siembra, cosecha y selección de semilla para reusarla en el siguiente ciclo. "Cuando las personas se casan", remarca Alux, "ellos heredan de sus padres semillas de maíz y frijol nativos". La nueva pareja usa esas semillas para iniciar su propia milpa. La milpa será la base de subsistencia de la nueva familia, de donde su comida va a provenir. "Mis padres recibieron semillas de mis abuelos, y cuando yo me casé, mi padre me dio semillas, y luego yo se las pasé a mis hijos, quienes se las pasarán a sus hijos también". ${ }^{14}$ Incluso cuando las personas no reciben tierra de sus padres - como es el caso de la mayoría de las mujeres, o cuando migran a otras regiones para crear una nueva comunidadlos campesinos heredan semillas que llevarán consigo a sus nuevas tierras. De esta manera, la herencia y reproducción de las semillas nativas simbolizan tanto la unión de la pareja como la reproducción de la comunidad con sus prácticas milenarias agrícolas y espirituales.

En la mayoría de las comunidades mestizas en la región, como Teopisca y Venustiano Carranza, los lazos espirituales con las semillas nativas son más débiles que en las comunidades indígenas. ${ }^{15}$ Sin embargo, la herencia de semillas también constituye una fuente fundamental de semillas para la nueva familia y juega un papel importante en el reforzamiento de la identidad campesina de esas comunidades. Don Antonio, que a sus 68 años aún trabaja su milpa en Teopisca, comenta que siete de sus nueve hijos comenzaron sus milpas usando semillas nativas provenientes de la familia. "Sólo mis dos hijos más pequeños, mi hijo y mi hija, no han recibido semillas porque ellos viven en la ciudad [de San Cristóbal]; están estudiando ahî", comenta con un sentimiento de incertidumbre. "Ya veremos qué pasa después de que terminen la escuela. Si no trabajan la tierra no van a necesitar las semillas", concluye. ${ }^{16}$ Una perspectiva similar viene de Diego, un joven tsotsil de 22 años de Zinacantán que trabaja en una ong en San Cristóbal. Él comentó repetidamente que necesitaba regresarse a su comunidad para iniciar su milpa, si no lo hacía no recibiría semillas de su familia. "Mis papás ya ni se acuerdan de mí", decía riendo frecuentemente. Un comentario muy subjetivo considerando que Diego visitaba a sus padres en su comunidad cada fin de semana. Estos dos ejemplos enfatizan la relación simbólica entre la herencia de semillas y la reproducción de estas familias como miembros de comunidades campesinas. Las semillas nativas, y junto con ellas los ancestros de sus comunidades, sólo son heredadas por aquellos que permanecen en la tierra. Esta dinámica social corresponde en parte a lo que Gómez (1997), en su estudio en la comunidad tseltal de

\footnotetext{
14 Alux, entrevista, febrero de 2016.

15 Ver Brush y Perales, 2007 y Perales, Benz y Brush, 2005 para un estudio sobre este tema en la región de Los Altos de Chiapas

16 Don Antonio, entrevista, febrero 2016.
} 
Tenejapa, identifica como el ethos maya, un sistema de valores que da prioridad al aprendizaje y desarrollo de la sabiduría como mecanismos para alcanzar prestigio y poder en la comunidad. Prestigio y poder están directamente vinculados con el conocimiento profundo de la milpa y el devenir de los individuos como "personas de cultivo", una construcción social que da sentido de identidad a los miembros de la comunidad a través de la práctica agrícola (D’Alessandro y González, 2017).

La centralidad de las relaciones de parentesco en la reproducción de los sistemas de semillas comunitarios refleja el hecho de que hoy en día entre $90 \%$ y $95 \%$ de todas las semillas plantadas en la región de estudio provienen de la propia comunidad. De hecho, la adquisición de maíz y frijoles — los dos cultivos básicos en la región- está prácticamente limitada a los procesos de herencia e intercambio, lo cual significa que estas semillas se encuentran prácticamente fuera de los circuitos comerciales. ${ }^{17}$ "Aquí en la comunidad no tenemos semillas de afuera. Nunca hemos recibido semilla de los programas gubernamentales", comenta Petul, un hombre tseltal de 43 años, zapatista de Cancuc. "Lo que a veces hacemos aquí es que intercambiamos semillas entre las familias, pero sólo hacemos eso con semillas locales, semillas que provienen de la propia comunidad —eso es, semillas nativas". Y concluye: "afortunadamente aún somos autosuficientes en semilla. Nosotros sembramos, cultivamos y reproducimos aquí las semillas que hay en nuestra comunidad". ${ }^{18}$

\section{El maíz nativo, el sistema de milpa y la agricultura de subsistencia}

Cuando se les pregunta a las personas de las comunidades en la región de estudio cómo se perciben a sí mismas como campesinos, tanto indígenas como mestizos se refieren invariablemente al maíz y la milpa. "Nosotros vivimos del maíz que cultivamos en la milpa", dice Susana, una mujer mestiza de 31 años no zapatista de Teopisca. "Aquí en mi comunidad todas las personas viven de sus milpas, nosotros principalmente producimos maíz y frijoles". ${ }^{19}$ Raymundo, un joven mestizo de 22 años no zapatista de Venustiano Carranza, comenta: "mi familia come de la milpa, de la tierra que nos heredaron nuestros padres y abuelos". ${ }^{20}$ Agustina, una mujer ch'ol de 37 años de Tumbalá, explica: "en nuestras comunidades, la primera comida que les damos a los niños después de la leche de sus madres es atole de maíz".21

\footnotetext{
17 Ver Brush y Perales, 2007: 217-219 para un análisis complementario en Los Altos; Sotelo, 2017 para un estudio en Las Margaritas, y Badstue et al., 2007 para un estudio en los valles centrales de Oaxaca.

18 Petul, entrevista, marzo de 2016.

${ }^{19}$ Susana, entrevista, marzo de 2016.

${ }^{20}$ Raymundo, entrevista, octubre de 2015.

${ }^{21}$ Agustina, entrevista, octubre de 2015.
} 
Más allá de su contribución a la seguridad alimentaria de los hogares, la mayoría de los indígenas campesinos también se refirieren a la relevancia cultural e histórica que el maíz tiene para las comunidades mayas. "El maíz es nuestro guardián. Siempre ha sido de esta manera", 22 comenta José, un hombre tseltal de 67 años no zapatista. Juanita, una mujer tseltal de 81 años y zapatista de Tenejapa, concuerda: "el maíz es el único alimento que siempre comemos, y no podemos vivir sin él. El maíz es como nuestro espíritu, nuestro ch'ulel, como le decimos aquí". ${ }^{23}$ Estas percepciones culturales son transmitidas de generación en generación. "Desde que somos bien chiquitos, casi en cuanto empezamos a caminar y hablar, nos enseñan que nosotros dependemos del maíz para nuestra existencia. 'Tienes que cuidar el maíz', eso es algo que mis abuelos siempre nos han dicho", ${ }^{24}$ comenta Lorenzo, un joven zapatista tsotsil de 19 años de Zinacantán.

Algunas otras personas incluso se refieren indirectamente al Popol Vuh, una narrativa de tradición precolombina que recuenta la creación de la tierra y la humanidad. "Existen textos muy antiguos que explican nuestra historia como pueblos mayas. Ahí se dice que nosotros fuimos creados del maíz”, explica Loxa, una joven zapatista tsotsil de 23 años que trabaja como promotora de educación en su comunidad. "Nosotros siempre hemos vivido en estas tierras porque es aquí donde los dioses que crearon a la humanidad encontraron primero al maíz. Mi abuela siempre decía que los dioses usaron al maíz para crearnos a nosotros, los humanos", ${ }^{25}$ agrega. Usando diferentes palabras, Isabela, una mujer tsotsil no zapatista de 78 años de San Andrés, expresa una idea similar: "Nosotros somos el pueblo del maíz. Comemos maíz porque fuimos creados del maíz. Nuestros ancestros fueron hechos de maíz, y así nosotros también”. ${ }^{26}$

El hecho de que respuestas tan similares provengan de personas de diferente género, edad, etnicidad y afiliación política en la región sugiere que estas narrativas son colectivas y están profundamente enraizadas dentro de las comunidades de la región. Sin embargo, no son percepciones abstractas, sino que tienen fundamentos materiales que están presentes en la vida diaria de las comunidades. Hoy en día, prácticamente todos los campesinos en la región de estudio que tienen acceso a la tierra continúan trabajando sus milpas y produciendo maíz para su propia subsistencia. Este es el caso incluso si los hogares tienen otras fuentes de ingreso tales como producción de cultivos para el mercado (café, chile), subsidios gubernamentales, remesas o salarios provenientes del mercado laboral. ${ }^{27}$ Como lo señalan Eakin et al. (2014) en su estudio sobre la producción campesina de maíz en Chiapas, la agricultura de subsistencia persiste como un componente

${ }^{22}$ José, entrevista, enero de 2016.

${ }^{23}$ Juanita, entrevista, marzo de 2016.

24 Lorenzo, entrevista, diciembre de 2015.

${ }^{25}$ Loxa, entrevista, diciembre de 2015.

${ }^{26}$ Isabela, entrevista, febrero de 2016.

27 Ver Isakson, 2009 para un análisis en la región maya de Guatemala, y Eakin et al., 2014 para una comparación entre Chiapas, el Estado de México y Sinaloa. 
central de la práctica agrícola, independientemente del grado de participación comercial de los hogares en el mercado.

Trabajar en la milpa y producir maíz para el autoconsumo son precisamente los fundamentos materiales que han sostenido a la civilización maya por milenios, y están intrínsecamente ligados al origen del maíz y su domesticación por los pueblos mesoamericanos (Wilkes, 2004; Buckler y Stevens, 2005; Piperno et al., 2009).

\section{El sistema de milpa y la seguridad alimentaria}

La milpa es un sistema agrícola centrado en el cultivo del maíz. En términos más amplios, la milpa es también un sistema de manejo de recursos naturales que fue completamente desarrollado por los pueblos mesoamericanos hace aproximadamente dos mil años, aunque sus orígenes datan de entre cuatro y tres mil años atrás (Ford y Nigh, 2009). El modelo de milpa tradicional —el cual crecientemente ha cedido su lugar a cuasi-monocultivos de maíz en tierras pobres que pocas veces o nunca son rotadas - consiste en maíz intercalado con otras especies, comúnmente frijoles, calabazas y quelites, pero también se suelen incorporar otros cultivos seleccionados de entre más de cien especies que fueron domesticadas en tiempos precolombinos (chile, cacao, jitomate, tabaco, vainilla, chayote, papaya, aguacate) y complementadas hoy en día con nuevas especies provenientes de otras partes del mundo (Wilkes, 2004; Nigh y Diemont, 2013).

En sus formas más complejas, el sistema tradicional de la milpa es un sistema de manejo de recursos naturales que consiste en cuatro ecozonas interconectadas: milpa, acahual o bosque secundario, bosque primario y sistemas de agua. La explotación sustentable y la preservación de las cuatro ecozonas -que incluye como componente central la regeneración continua de las zonas deforestadas, un proceso que puede tomar entre ocho y 20 años dependiendo de la región y de si se busca la regeneración del acahual o del bosque primario- permitió a las comunidades mayas reproducir este sistema de producción de alimentos por milenios (Nations y Nigh, 1980). El sistema milpa probó ser adaptable a los sumamente variables ecosistemas y culturas de Mesoamérica y se puede encontrar tanto a nivel del mar como en altitudes mayores a los 3,000 metros, así como en áreas húmedas-tropicales o semi-desérticas (Nigh y Diemont, 2013; Perales y Golicher, 2014).

Sin embargo, desde el siglo pasado, la resiliencia del sistema de milpa ha sido seriamente amenazada. Esto se debe en gran medida a que el ciclo orgánico de largo plazo entre cultivo y descanso de la tierra, el cual había permitido el balance sustentable entre las cuatro ecozonas, ha sido considerablemente alterado - limitado o eliminado por completo en algunas áreas, incluyendo muchas de las comunidades analizadas en este estudio. El incremento en la frecuencia del cultivo (la cantidad de tiempo que una parcela es cultivada en relación con el tiempo que se deja descansar) se ha convertido en una estrategia común de 
intensificación agrícola en la región maya. ${ }^{28}$ Un buen ejemplo de este proceso es dado por Marcelo, a quien cité anteriormente: "en mi familia [se refiere a su familia extendida con quien comparte cuatro hectáreas] tenemos ahora tres espacios en los cuales rotamos la milpa. Trabajamos la tierra por tres o cuatro ciclos [anuales] y después permitimos que descanse por dos o tres años. No podemos darle más tiempo porque no tenemos suficiente tierra. Necesitamos continuar produciendo nuestra comida". ${ }^{29}$

No existen suficientes datos para determinar cuándo exactamente comenzó el deterioro de la milpa en la región maya, ${ }^{30}$ pero el punto de inflexión podría ser entre los años de 1960 y 1970 . Entre los factores más relevantes que han influenciado este proceso se encuentran: crecimiento poblacional, escasez de tierra, uso intensivo de agroquímicos, producción casi de monocultivo, expansión de ganado, deforestación crónica y un incremento en la incorporación de los campesinos al mercado laboral, incluyendo migración de largo plazo. ${ }^{31} \mathrm{Ma}-$ nuel, un hombre tsotsil zapatista de 43 años de Zinacantán, ofrece un ejemplo de cómo estas dinámicas trabajan conjuntamente en su comunidad:

Aunque la milpa continúa siendo la principal fuente de comida en mi comunidad, el área de cultivo y la producción de comida ha disminuido ¿Por qué? Esto es así porque muchas personas han dejado la comunidad. Ahora las personas dejan la comunidad por seis meses, e incluso por uno o dos años... muchas familias también han introducido ganado como una alternativa porque es menos trabajo y te asegura algo de dinero en tiempo de crisis. También es una buena opción porque puedes poner tus animales en lugares donde la milpa ya no produce más [porque la tierra está deteriorada] y así mantienes la tierra ocupada. Cada familia tiene sus animales y eso ha reducido el área de cultivo. Y puedes ver cómo eso impacta la producción de alimentos porque ahora el maíz ya no dura todo el año, y entre junio y septiembre, tal vez hasta octubre, las personas necesitan comprar maíz para completar sus cosechas. Y eso ocurre con mi familia también. ${ }^{32}$

Como lo demuestran muchas comunidades en este estudio, "la milpa tradicional" paulatinamente ha cedido su lugar a la milpa en su nivel más básico, que literalmente significa un "campo de maíz" en el que se cultivan una o dos variedades (de los 22 tipos de maíz registrados en el estado, Brush y Perales, 2007) y se mantiene con el uso intensivo de agroquímicos. ${ }^{33}$ En las siguientes secciones se discuten con mayor detalle estos factores y sus implicaciones.

${ }^{28}$ Ver, por ejemplo, Ochoa y González, 2000: 31; Schmook, 2010: 234.

${ }^{29}$ Marcelo, entrevista, octubre de 2015.

30 De acuerdo con Nations y Nigh (1980), gran parte del conocimiento tecnológico indígena se perdió durante el proceso de colonización del pueblo maya por los españoles.

31 Para estudios enfocados en la región maya ver Isakson, 2009; Ochoa y González, 2000; Busch y Geohegan, 2010; Schmook, 2010.

32 Manuel, entrevista, noviembre de 2015.

33 Aunque este modelo "minimizado" de la milpa como cuasi-monocultivo contrasta marcadamente con los modelos más complejos descritos arriba, sobre todo con el jardín forestal maya, es 
El uso de agroquímicos es actualmente una práctica prevalente en las comunidades de estudio, tanto indígenas como mestizas, incluyendo zapatistas y no zapatistas. Por ejemplo, en un trabajo donde se analiza la producción de maíz en Los Altos de Chiapas, Eakin et al. (2014) encontraron que, entre los hogares enfocados en agricultura de subsistencia, 94.8\% usa fertilizantes, 78.7\% herbicidas y $36.9 \%$ insecticidas. Entre los hogares que producen algún excedente para el mercado, los porcentajes se incrementan a 99.6\% para el uso de fertilizantes, 93.3\% de herbicidas, y 71.9\% para insecticidas (ver también Bernardino et al., 2016).

El uso generalizado de agroquímicos ha tenido diversos impactos en estas comunidades, el más evidente es el cambio en las formas en que los campesinos trabajan la tierra. José, un hombre tseltal zapatista de 66 años de Tenejapa, reflexiona sobre este tema: "la forma en la que solíamos trabajar la tierra ha cambiado. Más que la forma de cuidar las semillas, lo que ha cambiado es cómo limpiamos y preparamos la tierra. Antes, todas las personas en la comunidad, incluyendo a mi propia familia, solíamos limpiar la tierra con nuestros machetes y otras herramientas. Antes, estoy hablando de los años de 1970. Ese fue el periodo cuando el gobierno nos trajo por primera vez un programa y nos dio fertilizantes y algunos químicos para matar la maleza y preparar la tierra para su cultivo". Después de reflexionar por algunos minutos, agrega: "esto ha modificado la producción en la milpa. Algunas veces las personas dicen que 'la milpa da más' cuando pones los químicos, otras veces que 'la tierra ya no produce' si no la alimentas con los químicos. Entonces, vemos cómo las personas se han vuelto cada vez más dependientes de los químicos para trabajar la tierra”. ${ }^{34}$

En un contexto diferente - el taller de soberanía de las semillas en la parroquia de San Andrés mencionado anteriormente- Joel, un hombre no zapatista de 42 años, se dirige a la audiencia: "Nuestras milpas están muy tristes porque las hemos contaminado con los químicos. De todas las personas aquí [136 representantes de las nueve regiones de la parroquia], sólo tres no usamos químicos". Y pregunta retóricamente: “¿por qué estamos haciendo esto hermanos?"35 "Porque así es más fácil”, responde Marcelino, un cura de una comunidad tseltal en Cancuc quien promueve métodos orgánicos de agricultura en la región, cuando le planteo la misma pregunta. "En lugar de usar tus propias manos y el machete, puedes matar la maleza y los animales con sólo esparcir el químico. Eso es mucho menos trabajo y ahorras mucho tiempo. Con los químicos resuelves las cosas

importante reiterar que los campesinos continúan denominando sus campos de maíz como milpas y por lo tanto esta denominación mantiene validez como unidad de estudio. Aunque es útil contrastar el modelo "tradicional" o histórico de la milpa descrito por académicos con el modelo real contemporáneo reproducido por los campesinos, sobre todo con el objetivo de estudiar su evolución, es necesario evitar cualquier idealización de lo que la milpa "debería de ser".

${ }^{34}$ José, entrevista, enero de 2016.

35 Joel, grabación, octubre de 2015. 
mucho más rápido. Producir orgánico requiere mucho trabajo, y muchas personas ya no lo quieren hacer, particularmente ahora que muchos de ellos trabajan fuera de sus tierras". ${ }^{36}$ Además de ahorrar tiempo, el uso de agroquímicos también resuelve parcialmente el problema creciente de escasez de mano de obra familiar gratuita, la cual históricamente ha sido un eje central del sistema de milpa (Wasserstrom, 1977; Nations y Nigh, 1980).

\section{Deterioro ambiental, cambio climático e inseguridad alimentaria}

Aunque el uso de agroquímicos ha traído algunos beneficios a las comunidades, particularmente la reducción del trabajo requerido para sostener la milpa, es evidente que los costos de esta estrategia han superado por mucho sus beneficios. Entre los costos podemos identificar una dependencia generalizada a los agroquímicos y sus consecuentes impactos negativos en el medio ambiente y la salud. "El mayor impacto del uso de agroquímicos es que el suelo se empobrece", comenta Jtin, un hombre tseltal de 32 años, zapatista de Tenejapa: "Con los químicos lo que sucede es que cuando quemas la maleza todo desaparece del suelo, lo matas todo y el suelo se queda pelón. Entonces, cuando llueve, el suelo se erosiona y eso hace la tierra mucho más pobre". ${ }^{37}$

Más allá del deterioro de la tierra, los campesinos también asocian el uso de agroquímicos con la contaminación de las fuentes de agua y el deterioro del maíz y las semillas nativas. "Cuando los químicos se usan, los ríos, las venas de la tierra, el agua, todo se contamina; cada fuente de agua se envenena", ${ }^{38}$ dice Rosa, una mujer no zapatista ch'ol de Tumbalá. Muchos campesinos hacen eco de la preocupación de que las semillas estén siendo afectadas por el uso de agroquímicos. "Las semillas han reducido su tamaño; tanto la mazorca como los granos del maíz se han hecho más chiquitos. Es como si se hubieran hecho estériles, como si una modificación de sus células, de su corazón, hubiese ocurrido", reflexiona Ana, una mujer mestiza de 39 años no zapatista de Tumbalá. "También podemos ver cómo muchas semillas se echan a perder más fácilmente ahora, ya no resisten bien. Tal vez hay nuevas plagas y enfermedades. Nosotros no sabemos bien porque no estudiamos, pero sí podemos decir que esto no pasaba antes", ${ }^{39}$ agrega. Agustino, un hombre tseltal no zapatista de Cancuc, relaciona el deterioro de las semillas con la productividad de la milpa: "Ahora cultivamos muy pocas cosas porque la tierra está enferma... nuestro maíz también está enfermo, ahora se pone amarillo, el maíz no está muy bien que digamos". ${ }^{40}$

\footnotetext{
36 Marcelino, entrevista, febrero de 2016.

37 Jtin, entrevista, febrero de 2016.

38 Rosa, entrevista, marzo de 2016.

${ }^{39}$ Ana, entrevista, febrero de 2016.

${ }^{40}$ Agustino, entrevista, febrero de 2016.
} 
Junto con las contribuciones potenciales de los agroquímicos al deterioro de la milpa, existen otros problemas medioambientales en el área de estudio que podrían estar relacionados con el cambio climático. Los temas mencionados con mayor frecuencia son las modificaciones en la temporada de lluvias y la presencia de enfermedades y plagas en los cultivos. Por ejemplo, prácticamente todas las comunidades indígenas que integran parte de este estudio mencionaron la "roya", una enfermedad del café que se ha expandido a través de la región en los últimos siete años, como uno de sus principales problemas.

Por su parte, las comunidades mestizas localizadas en la región de Venustiano Carranza han sido severamente afectadas por una sequía que, al momento del trabajo de campo, había durado ya más de cuatro años. La falta de lluvia ha tenido efectos devastadores en la seguridad alimentaria de los hogares. Maricela, una mujer de 24 años y madre de dos niños, explica: "los últimos años han sido muy feos porque no hemos tenido suficiente lluvia y hemos perdido nuestras cosechas". Maricela comienza a llorar, y su hermana, Esmeralda, de 32 años y madre de tres niños, retoma la conversación: "No ha habido suficiente comida y hemos tenido hambre. El año pasado ni siquiera tuvimos frijoles, sólo tortillas y pozol. Los pocos frijoles que tuvimos se los dimos a los niños. Al menos algunos días ellos podían tener una tortilla con frijol. La situación ha sido terrible". ${ }^{4}$

En estas condiciones adversas, la economía de los hogares se ve aún más afectada porque las familias tienen que gastar el poco dinero en efectivo que tienen en comprar comida que de otra manera podría ser producida en la milpa. "Ahora tenemos que comprarlo todo, incluyendo el maíz y los frijoles. No tenemos verduras y nunca comemos fruta... Tenemos que completar con algo de maíz que compramos en Santa Lucía [un poblado vecino, a una hora de distancia], pero es muy caro. Una cubeta [aproximadamente $20 \mathrm{~kg}$ de maíz] cuesta 100 pesos. Algunas veces, si tenemos un poco de dinero extra, también compramos unos pocos frijoles", ${ }^{42}$ explica Jaime, un hombre de 32 años y padre de tres niños.

Tomadas en conjunto, estas narrativas nos ofrecen una imagen de cómo las comunidades experimentan los efectos interconectados de inseguridad alimentaria, degradación medioambiental y cambio climático, algunos de los cuales parecen estar relacionados con el uso intensivo de agroquímicos y el consecuente deterioro de la milpa.

\section{Discusión}

En las secciones anteriores describimos y analizamos algunos de los múltiples significados que las comunidades campesinas de la región central de Chiapas asignan a sus semillas nativas y a la milpa. De este análisis se destaca que las

\footnotetext{
${ }^{41}$ Maricela y Esmeralda, entrevista conjunta, marzo de 2016.

42 Jaime, entrevista, marzo de 2016.
} 
prácticas de conservación, reproducción y consumo de maíz nativo desempeñan un papel central en la organización de las estructuras agrarias, socioculturales, espirituales, e incluso políticas que rigen a estas comunidades. Dos de los principales argumentos que se pueden derivar del presente estudio son: primero, que el sistema informal de herencia de semillas nativas de padres a hijos juega un papel estratégico en el ensamblaje de estas estructuras. Segundo, que las emociones que subyacen el compromiso moral que asumen los hijos al heredar semillas de sus padres son determinantes para entender la forma en la que los campesinos perciben los riesgos potenciales impuestos por los fenómenos de degradación medioambiental y cambio climático sobre su agricultura de subsistencia, esto es, sobre sus milpas y semillas. El compromiso moral de reproducir las condiciones medioambientales y sociales para que las próximas generaciones puedan también vivir de la tierra y el maíz ayuda a explicar, desde una perspectiva emocional y psicológica, por qué los campesinos de estas comunidades han optado por intentar mitigar estos riesgos en lugar de abandonar la milpa.

La decisión de los campesinos de perseverar en la reproducción de la milpa no es banal si consideramos el contexto adverso para la agricultura de subsistencia descrito en las secciones anteriores, donde se conjugan escasez de recursos productivos de buena calidad, fenómenos ambientales con impactos severos y cambios estructurales en la organización de las comunidades derivados de su creciente integración al mercado. Este estudio expande el análisis de Isakson (2009) sobre los valores no económicos que motivan a los campesinos indígenas de Guatemala a continuar reproduciendo su milpa a pesar de su creciente incorporación al mercado. Como lo argumenta el autor, entender las motivaciones de los campesinos para mantenerse apegados a la milpa más allá de la racionalidad económica, particularmente cuando "no hay ganancia en la milpa", como lo aseveran los campesinos de Guatemala, contribuye a complejizar el análisis sobre la cuestión agraria (Van der Ploeg, 2010; Akram-Lodhi y Kay 2010a y 2010b; Bernstein, 2011; McMichael, 2013) y a entender por qué la creciente participación de los campesinos en la economía de mercado no ha implicado el abandono de la tierra (Isakson, 2009: 753). Nuestro estudio, enfocado en Chiapas, contribuye a identificar y entender con mayor profundidad algunos de los valores no monetarios que determinan la racionalidad de los hogares campesinos, no sólo frente a las fuerzas del mercado sino también del medio ambiente, así como su autodefinición como hombres del maíz que viven de la tierra.

Más aún, los valores culturales y espirituales que las comunidades asignan a su maíz y a la milpa son determinantes en la propia definición de los campesinos como seres humanos y entes políticos capaces de definir su organización social, sus prácticas agrícolas y sus luchas sociales. Como lo sugiere Scott en Weapons of the Weak (1985), la agricultura de subsistencia ciertamente se trata de seguridad alimentaria, pero también es con frecuencia un arma política efectiva usada por los sectores más marginados de la sociedad para resistir, al menos parcialmente, el poder del estado y las dinámicas de integración a la "civilización". El gran 
énfasis que el movimiento zapatista ha puesto en fortalecer la agricultura de subsistencia en sus comunidades como estrategia de resistencia política, que se resume en uno de los lemas más populares de la región, "sin comida no hay resistencia", confirma la tesis de Scott incluso en el siglo xxı (Hernández, Perales y Jaffee, en prensa).

Este estudio de caso ilustra al menos dos paradojas que vale la pena destacar. La primera es que si bien los agroquímicos han contribuido al deterioro ambiental de las comunidades, afectando aparentemente la sustentabilidad a largo plazo del sistema actual de agricultura de subsistencia, también se han constituido en una herramienta esencial para la reproducción de la milpa. Los agroquímicos han ayudado a los campesinos a resolver parcialmente tres problemas crecientes: la escasez de mano de obra familiar gratuita, la escasez de buena tierra para cultivo y el alto deterioro del suelo de siembra. Como lo mencionan varios campesinos en las entrevistas, "el suelo no da maíz si no lo alimentas con el químico [fertilizante]" ${ }^{43}$ En este sentido, los agroquímicos han permitido a los campesinos mantener su agricultura de subsistencia en lugar de recurrir por completo al mercado para satisfacer sus necesidades alimenticias. Dicho devenir también adhiere complejidad a la cuestión agraria al mostrar una realidad compleja en que la agricultura de subsistencia, al menos en la región de estudio, está intrínsecamente ligada a la agricultura industrial y, por lo tanto, al mercado. Un elemento que valdría la pena estudiar a profundidad en el futuro es la capacidad estructural de estas comunidades campesinas, más allá de cualquier discurso político, para iniciar y completar exitosamente la transición del modelo convencional de agricultura hacia el modelo agroecológico, tal y como lo ha propuesto el EzLN.

Otra paradoja interesante concierne a la evolución del movimiento local de soberanía de las semillas. Es relevante notar que el origen del movimiento es un rechazo generalizado a los ogms y a los derechos de propiedad intelectual sobre el germoplasma, dos elementos externos que no afectan directamente, al menos por ahora, a las comunidades debido a que su agricultura de subsistencia aún depende enteramente de las semillas nativas; lo cual quiere decir que estas comunidades preservan su soberanía sobre sus semillas. Tal estrategia de movilización política en torno a amenazas externas, no obstante, ha probado ser útil para abrir la discusión sobre otros riesgos más tangibles y directos a la soberanía de estas comunidades sobre sus semillas, fundamentalmente deterioro ambiental, cambio climático y el modelo actual de agricultura campesina basado en prácticas de intensificación agrícola. En este proceso de desarrollo político, el abandono de los agroquímicos se ha constituido, al menos retóricamente, en un objetivo central del movimiento social.

De esta manera, el movimiento local por la soberanía de las semillas ha devenido de forma subyacente en un movimiento social en contra de los precep-

${ }^{43}$ José Juan, entrevista, enero 2016. 
tos tanto del sistema agroalimentario neoliberal ${ }^{44}$ como de la Revolución Verde. Dicho resultado es destacable si consideramos que las comunidades nunca han adoptado las semillas industriales —el insumo más importante de los paquetes tecnológicos de la Revolución Verde- ni los ogms. No obstante, aunque la Revolución Verde no logró desplazar las semillas nativas de estas comunidades -el efecto más esperado-, su proyecto político-tecnológico ha tenido un gran impacto en los sistemas agrarios y medioambientales de la región por medio de la quimicalización de la agricultura de subsistencia. Más aún, debido a su impacto negativo en el medio ambiente, los agroquímicos parecen haberse constituido, al pasar de las décadas, en una de las amenazas más directas a la sustentabilidad de la milpa y, por lo tanto, a la soberanía de las comunidades sobre sus semillas. El presente estudio contribuye a una mejor comprensión sobre el surgimiento y evolución de los movimientos sociales campesinos en el contexto de la Revolución Verde y del sistema agroalimentario neoliberal (Schurman y Munro, 2010; McMichael, 2014, 2016).

Finalmente, esta investigación también contribuye a un mejor entendimiento de las relaciones entre las comunidades campesinas y la naturaleza. Por una parte, el análisis sobre los valores asignados al maíz y la milpa complementan estudios previos que han trabajo en detalle tal temática. ${ }^{45}$ Por otra parte, el análisis sobre la milpa y los agroquímicos refleja la importancia de destacar la agencia del campesinado como ente político responsable de sus elecciones socio-técnicas en el agro, lo cual nos previene de idealizar el papel de las comunidades campesinas como guardianas inminentes de la madre tierra y en abierta oposición con los preceptos occidentales de ciencia y tecnología. Este estudio sugiere que las fronteras entre "el mundo occidental" y "el mundo indígena como alteridad" (ver, por ejemplo, Estrada, 2009) son flexibles, y que el pragmatismo de los campesinos muchas veces se contrarresta con elementos que los observadores externos asociamos con "la cosmovisión indígena", por ejemplo, la prioridad de mantener una relación armónica entre hombres y naturaleza. Al mismo tiempo, no resulta sorprendente que sean estas mismas autodefiniciones como "guardianes de la madre tierra y las semillas" u "hombres del maíz" o los valores espirituales asignados a la naturaleza, por ejemplo, la idea de que el maíz nativo encarna el espíritu de los ancestros de los campesinos, las que permitan a comunidades enteras movilizarse políticamente en luchas de carácter anticolonial en defensa de su territorio, sus semillas y su agricultura de subsistencia, particularmente frente a un enemigo común, que bien puede ser el gobierno, empresas transnacionales con sus insumos industriales y derechos de propiedad intelectual, o incluso fenómenos medioambientales como el cambio climático. Este artículo ilustra una

\footnotetext{
${ }^{44}$ Ver McMichael, 2016; Friedmann, 2016; Bernstein, 2016 para un análisis crítico de lo que se denomina en la literatura como "neoliberal agri-food system".

${ }^{45}$ Ver, por ejemplo, dos artículos publicados en esta misma revista, D’Alessandro y González, 2017 y Estrada, 2009 para un análisis en la región de Los Altos de Chiapas.
} 
cosmovisión campesina e indígena muy flexible, dinámica y pragmática y con un gran potencial político.

\section{Bibliografía}

Akram-Lodhi, Harron y Cristóbal Kay

2010a "Surveying the Agrarian Question (Part 1): Unearthing Foundations, Exploring Diversity”, The Journal of Peasant Studies, 37 (1): 177-202. Dol: https://doi. org/10.1080/03066150903498838.

2010b "Surveying the Agrarian Question (Part 2): Current Debates and Beyond", The Journal of Peasant Studies, 37 (2): 255-284. Dor: https://doi. org/10.1080/03066151003594906.

Altieri, Miguel y Clara Nicholls

2013 "The Adaptation and Mitigation Potential of Traditional Agriculture in a Changing Climate", Climate Change, 140 (1): 33-45. Dor: https://doi. org/10.1007/s10584-013-0909-y.

Badstue, Lone, Mauricio Bellon, Julien Berthaud, Alejandro Ramírez y Xóchitl Juárez

2007 "The Dynamics of Farmers' Maize Seed Supply Practices in the Central Valleys of Oaxaca, Mexico", World Development, 35 (9): 1579-1593. Dol: https:// doi.org/10.1016/j.worlddev.2006.05.023.

Bellon, Mauricio, Ehsan Dulloo, Julie Sardos, Imke Thormann y Jeremy Burdon

2017 "In Situ Conservation-Harnessing Natural and Human-Derived Evolutionary Responses to Ensure Future Crop Adaptation”, Evolutionary Applications, 10: 965-977. DoI: https://doi.org/10.1111/eva.12521.

Bellon, Mauricio, David Hodson y Jon Hellin

2011 "Assessing the Vulnerability of Traditional Maize Seed Systems in Mexico to Climate Change", PNAS, 108 (33): 13432-13437. DoI: https://doi.org/10.1073/ pnas. 1103373108 .

Bernardino Hernández, Héctor, Ramón Mariaca, Austreberta Nazar, José David Álvarez, Arturo Torres y Crispín Herrera

2016 "Factores socioeconómicos y tecnológicos en el uso de agroquímicos en tres sistemas agrícolas en Los Altos de Chiapas, México", Interciencia, 41 (6): 382-392.

Bernstein, Henry

2011 "Is There an Agrarian Question in the 21 $1^{\text {st }}$ Century?", Canadian Journal of Development Studies, 27 (4): 449-460. DoI: https://doi.org./10.1080/02255189. 2006.9669166.

2016 "Agrarian Political Economy and Modern World Capitalism: The Contributions of Food Regime Analysis", The Journal of Peasant Studies, 43 (3): 611647. Dor: https://doi.org/10.1080/03066150.2015.1101456. 
Brandt, Marisa

2014 "Zapatista Corn: A Case Study in Biocultural Innovation”, Social Studies of Science, 44 (6): 874-900. Dol: https://doi.org/10.1177/0306312714540060.

Brechin, Steven

2008 "Ostriches and Change: A Response to Global Warming and Sociology", Current Sociology, 56 (3): 467-474. Dol: https://doi.org/10.1177/0011392107088239.

Brown, Peter

2013 "Maya Mother Seeds in Resistance of Highland Chiapas in Defense of Native Corn", Seeds of Resistance, Seeds of Hope: Place and Agency in the Conservation of Biodiversity, pp. 151-176, Virginia Nazarea, Robert Rhoades y Jenna AndrewsSwann (eds.). Tucson: The University of Arizona Press.

Brulle, Robert

2013 "Institutionalizing Delay: Foundation Funding and the Creation of U.S. Climate Change Counter-Movement Organizations", Climate Change, 122 (4): 681-694.

Brush, Stephen y Hugo Perales

2007 "A Maize Landscape: Ethnicity and Agro-Biodiversity in Chiapas Mexico", Agriculture, Ecosystems \& Environment, 121 (3): 211-221. Dol: https://doi. org/10.1016/j.agee.2006.12.018.

Buckler, Edward y Natalie Stevens

2005 "Maize Origins, Domestication, and Selection”, Darwin's Harvest, pp. 67-90, Timothy Motley, Nyree Zerega y Hugh Cross (eds.). Nueva York: Columbia University Press.

Busch, Christopher y Jaqueline Geohegan

2010 "Labor Scarcity as an Underlying Cause of the Increasing Prevalence of Deforestation Due to Cattle Pasture Development in the Southern Yucatan Region", Regional Environment Change, 10 (3): 191-203. DoI: https://doi. org/10.1007/s10113-010-0110-z.

Climate Change Performance Index (CCPI)

2019 Climate Change Performance Index 2020. < https://www.climate-change-performance-index.org/the-climate-change-performance-index-2020> [consultado el 2 de enero de 2020].

Cline, William

2008 "Global Warming and Agriculture”, Finance and Development, March: 23-27.

Coomes, Oliver, Shawn McGuire, Eric Garine, Sophie Caillon, Doyle McKey, Elise Demeulenaere, Devra Jarvis, Guntra Aistara, Adeline Barnaud, Pascal Clouvel, Laure Emperaire, Selim Louafi, Pierre Martin, Francois Massol, Marco Pautasso, Chloe Violon y Jean Wencelius

2015 "Farmer Seed Networks Make a Limited Contribution to Agriculture? 
Four Common Misconceptions", Food Policy, 56: 41-50. Dol: https://doi. org/10.1016/j.foodpol.2015.07.008.

D’Alessandro, Renzo y Alma Amalia González

2017 "La práctica de la milpa, el ch'ulel y el maíz como elementos articuladores de la cosmovisión sobre la naturaleza entre los tseltales de Tenejapa en Los Altos de Chiapas”, Estudios de Cultura Maya, L: 271-297. Dor: https://doi. org/10.19131/iifl.ecm.2017.50.768.

Della Porta, Donatella y Mario Diani

2009 Social Movements. An Introduction, $3^{\text {a }}$ edición. Massachusetts: Blackwell Publishing.

Della Porta, Donatella y Louisa Parks

2014 "Framing Processes in the Climate Movement", Routledge Handbook of Climate Change Movement, pp. 19-30, Matthias Dietz y Heiko Garrelts (eds.). Nueva York: Routledge.

Diócesis de San Cristóbal de Las Casas

2014 Congreso de la Madre Tierra: comunicado final. < http://oclacc.org/redes/teologia/2014/02/congreso-de-la-madre-tierra-comunicado-final/> [consultado el 11 de enero de 2020].

Dunlap, Riley E. y Robert J. Brulle (eds.)

2015 Climate Change and Society. Sociological Perspectives. Nueva York: Oxford University Press.

Eakin, Hallie, Hugo Perales, Kirsten Appendini y Stuart Sweeney

2014 "Selling Maize in Mexico: The Persistence of Peasant Farming in an Era of Global Markets", Development and Change, 45 (1): 133-155. Dor: https://doi. org/10.1111/dech.12074.

Estrada Ochoa, Adriana

2009 "Naturaleza, cultura e identidad. Reflexiones desde la tradición oral maya contemporánea”, Estudios de Cultura Maya, XXXIV: 181-201. Dor: https://doi. org/10.19130/iifl.ecm.2009.34.35.

EZLN (Ejército Zapatista de Liberación Nacional)

2003 "Chiapas: La Treceava Estela”, Komanilel. < http://komanilel.org/BIBLIOTECA_VIRTUAL/treceava_estela.pdf > [consultado el 15 de enero de 2020].

FAO (Food and Agriculture Organization of the United Nations)

2019 Agriculture and Climate Change. Challenges and Opportunities at the Global and Local Level. Roma: Food and Agriculture Organization of the United Nations.

Ford, Anabel y Ronald Nigh

2009 "Origins of the Maya Forest Garden: Maya Resource Management", Journal of Ethnobiology, 29 (2): 213-236. Dol: https://doi.org/10.2993/0278-077129.2.213. 
Friedmann, Harriet

2016 "Commentary: Food Regime Analysis and Agrarian Questions: Widening the Conversation”, The Journal of Peasant Studies, 43 (3): 671-692. Dol: https://doi. org/10.1080/03066150.2016.1146254.

Gómez Muñoz, Maritza

1997 "Los aprendizajes comunitarios en Los Altos de Chiapas", Indígenas en la Escuela, pp. 53-84, María Bertely y Adriana Robles (coords.). México: Grupo Ideograma Editores.

Goodwin, Jeff y James Jasper (eds.)

2015 The Social Movements Reader. Cases and Concepts, $3^{\mathrm{a}}$ edición. Massachusetts: Willey Blackwell.

Hellin, Jon, Mauricio Bellon y Sarah Hearne

2014 "Maize Landraces and Adaptation to Climate Change in Mexico", Journal of Crop Improvement, 28 (4): 484-501. DoI: https://doi.org/10.1080/15427528.20 14.921800 .

Hernández, Carol

2018 "The Dispute Over the Commons: Seed and Food Sovereignty as Decommodification in Chiapas, Mexico", tesis de doctorado en Sociología. Portland: Portland State University.

Hernández, Carol, Hugo Perales y Daniel Jaffee

En prensa "Without Food there is No Resistance: The Impact of the Zapatista Conflict on Food and Seed Sovereignty and Agrobiodiversity Conservation in Chiapas, Mexico", Geoforum (número especial sobre el impacto de conflictos armados en la agrobiodiversidad).

IPCC (Intergovernmental Panel on Climate Change)

2019 Climate Change and Land. Disponible en: <https://www.ipcc.ch/srccl-reportdownload-page/> [consultado el 3 de septiembre de 2019].

Isakson, Ryan

2009 “ 'No Hay Ganancia en la Milpa': The Agrarian Question, Food Sovereingty, and the On-Farm Conservation of Agrobiodiversity in the Guatemalan Highlands", The Journal of Peasant Studies, 36 (4): 725-759. Dor: https://doi. org/10.1080/03066150903353876.

Jasper, James

2018 The Emotions of Protest. Chicago: The University of Chicago Press.

Jasper, James y Francesca Polletta

2018 "The Cultural Context of Social Movements", The Wiley Blackwell Companion to Social Movements, 14 (4): 63-78. Dol: https://doi.org/10.1002/9781119168577. ch3. 
Jones, Peter y Philip Thornton

2003 "The Impacts of Climate Change on Maize Production in Africa and Latin America in 2055", Global Environmental Change, 13: 51-59. Dol: https://doi. org/10.1016/S0959-3780(02)00090-0.

Lerna Rodríguez, Enriqueta

2015 "La pastoral de la Madre Tierra en Chiapas. Panorámica de la lucha persistente de un credo político-religioso”, Revista Iberoamericana de Teología, XI (21): 65-88.

Li, Xiang, Taro Takahashi, Nobuhiro Suzuki y Harry Kaiser

2011 "The Impact of Climate Change on Maize Yields in the United States and China”, Agricultural Systems, 104 (4): 348-353. Dol: https://doi.org/10.1016/j. agsy.2010.12.006.

López Intzín, Juan

2013 "Ich'el ta muk': la trama en la construcción mutua y equitativa del Lekil Kuxlejal (vida plena-digna)", Senti-pensar el género: perspectivas desde los pueblos originarios, pp. 73-106, Georgina Méndez, Juan López Intzín, Sylvia Marcos y Carmen Osorio (coords.). Guadalajara: Red Interdisciplinaria de Investigadores de los Pueblos Indios de México, Red de Feminismos Descoloniales y La Casa del Mago.

McAdam, Doug

2017 "Social Movement Theory and the Prospects for Climate Change Activism in the United States", The Annual Review of Political Science, 20: 189-208. Dol: https://doi.org/10.1146/annurev-polisci-052615-025801.

McCright, Aaron y Riley Dunlap

2016 "The Politicization of Climate Change and Polarization in the American Public's Views of Global Warming, 2001-2010”, The Sociological Quarterly, 52 (2): 155-194. DoI: https://doi.org/10.1111/j.1533-8525.2011.01198.x.

McMichael, Philip

2013 Food Regimes and Agrarian Questions. Halifax: Fernwood.

2014 "Historicizing Food Sovereignty", The Journal of Peasant Studies, 41 (6): 933957. DoI: https://doi.org/10.1080/03066150.2013.876999.

2016 "Commentary: Food Regime for Thought", The Journal of Peasant Studies, 43 (3): 648-670. DoI: https://doi.org/10.1080/03066150.2016.1143816.

Mercer, Kristin y Hugo Perales

2010 "Evolutionary Response of Landraces to Climate Change in Centers of Crop Diversity", Evolutionary Applications, 3 (5-6): 480-493. Dor: https://doi. org/10.1111/j.1752-4571.2010.00137.x.

Mercer, Kristin, Hugo Perales y Joel Wainwright

2012 "Climate Change and the Transgenic Adaptation Strategy: Smallholder Livelihoods, Climate Justice, and Maize Landraces in Mexico", Global En- 
vironment Change, 22 (2): 495-504. Dol: https://dx.doi.org/10.1016/j.gloenvcha.2012.01.003.

Morton, John F.

2007 "The Impact of Climate Change on Smallholder and Subsistence Agriculture", PNAS, 104 (50): 19680-19685. DoI: https://doi.org/10.1073/ pnas.0701855104.

Msowoya, Kondwani, Kaveh Madani, Rahman Davtalab, Ali Mirchi y Jay Lund

2016 "Climate Change Impacts on Maize Production in the Warm Heart of Africa", Water Resources Management, 30 (4): 5299-5312. Dol: https://doi.org/10.1007/ s11269-016-1487-3.

Nations, James y Ronald Nigh

1980 "The Evolutionary Potential of Lacandon Maya Sustained-Yield Tropical Forest Agriculture", Journal of Anthropological Research, 36 (1): 1-30.

Nelson, Gerald, Mark Rosegrant, Jawoo Koo, Richard Robertson, Timothy Sulser, Tingiu Zhu, Claudia Ringler, Siwa Msangi, Amanda Palazzo, Miroslav Batka, Marilia Magalhanes, Rowena Valmonte-Santos, Mandy Ewing y David Lee

2009 Climate Change. Impact on Agriculture and Costs of Adaptation. Washington, D.C.: International Food Policy Research Institute.

Nigh, Ronald y Stewart Diemont

2013 "The Maya Milpa: Fire and the Legacy of Living Soil", Frontiers in Ecology and the Environment, 11: e45-e54. Dol: https://doi.org/10.1890/120344.

Norgaard, Karie

2006 “'We Don’t Really Want to Know’: Environmental Justice and Socially Organized Denial of Global Warming in Norway", Organization and Environment, 19 (3): 347-370. Dol: https://doi.org/10.1177/1086026606292571.

2011 Living in Denial. Climate Change, Emotions, and Everyday Life. Massachusetts: The mIT Press.

Ochoa Gaona, Susana y Mario González-Espinosa

2000 "Land Use and Deforestation in the Highlands of Chiapas, Mexico", Applied Geography, 20 (2000): 17-42. DOI: 10.1016/S0143-6228(99)00017-X.

Perales, Hugo, Bruce Benz y Stephen Brush

2005 "Maize Diversity and Ethnolinguistic Diversity in Chiapas, Mexico", PNAS, 102 (3): 949-954. Dol: https://doi.org/10.1073/pnas.0408701102.

Perales, Hugo y Duncan Golicher

2014 "Mapping the Diversity of Maize Races in Mexico", Plos One, 9 (12): 1-20. Dol: https://doi.org/10.1371/journal.pone.0114657.

Piperno, Dolores, Anthony Ranere, Irene Holst, Jose Iriarte y Ruth Dickau

2009 "Starch Grain and Phytolith Evidence for Early Ninth Millennium B.P. Maize 
from the Central Balsas River Valley, Mexico”, PNAS, 106 (13): 5019-5024. Dol: https://doi.org/10.1073/pnas.0812525106.

Quist, David e Ignacio Chapela

2001 "Transgenic DNA Introgressed into Traditional Maize Landraces in Oaxaca, Mexico", Nature, 414 (6863): 541-543. Dor: https://doi.org/10.1038/35107068.

Roeser, Sabine

2012 "Risk Communication, Public Engagement, and Climate Change: A Role for Emotions", Risk Analysis, 32 (6): 1033-1040. Dol: https://doi.org/10.1111/ j.1539-6924.2012.01812.x.

Schmook, Birgit

2010 "Shifting Maize Cultivation and Secondary Vegetation in the Southern Yucatan: Successional Forest Impacts of Temporal Intensification", Regional Environment Change, 10 (3): 233-246. Dol: https://doi.org/10.1007/s10113-0100128-2.

Schools for Chiapas

2017 “GMo-Free Zapatista Seed Corn”, <http://www.schoolsforchiapas.org/store/ coffee-corn-and-agricultural/gmo-free-zapatista-seed-corn/> [consultado el 2 de enero de 2020].

Schurman, Rachel y William A. Munro

2010 Fighting for the Future of Food: Activists Versus Agribusiness in the Struggle over Biotechnology. Minneapolis: University of Minnesota Press.

Scott, James

1985 Weapons of the Weak. New Haven: Yale University Press.

Sotelo Paz, Clara Elizabeth

2017 "El parentesco en la transmisión de semillas campesinas en Las Margaritas, Chiapas", tesis de maestría en Ciencias en Recursos Naturales y Desarrollo Rural. México: El Colegio de la Frontera Sur-Chiapas.

Van der Ploeg, Jan Douwe

2010 "The Peasantries of the Twenty-First Century: The Commoditisation Debate Revisited", The Journal of Peasant Studies, 37 (1): 1-30. Dol: https://doi. org/10.1080/03066150903498721.

Vermeulen, Sonja

2014 Climate Change, Food Security and Small-Scale Producers. cCafs InfoBrief. Copenhagen: CGIAR Research Program on Climate Change, Agriculture and Food Security (CCAFS).

Vincent, Holly, John Wiersema, Shelagh Kell, Hannah Fielder, Samantha Dobbie, Nora Castañeda-Álvarez, Luigi Guarino, Ruth Eastwood, Blanca León y Nigel Maxted

2013 "A Prioritized Crop Wild Relative Inventory to Help Underpin Global Food 
Security”, Biological Conservation, 167: 265-275. DoI: https://doi.org/10.1016/j. biocon.2013.08.011.

Wasserstrom, Robert

1977 "Land and Labour in Central Chiapas: A Regional Analysis", Development and Change, 8 (4): 441-463. DoI: https://doi.org/10.1111/j.1467-7660.1977. tb00750.x.

Weber, Elke

2015 "What Shapes Perceptions of Climate Change? New Research Since 2010", WIREs Climate Change, 7 (1): 332-342. Dor: https://doi.org/10.1002/wcc.377.

Wilkes, Garrison

2004 "Corn, Strange and Marvelous: But Is a Definitive Origin Known?”, Corn. Origin, History, Technology, and Production, pp. 3-63, Wayne Smith, Javier Betrán y Arthur Runge (eds.). Hoboken: Wiley.

Zerubavel, Evitar

2002 "The Elephant in the Room: Notes on the Social Organization of Denial", Culture in Mind: Toward a Sociology of Culture and Cognition, pp. 21-27, Karen Cerulo (ed.). Nueva York: Routledge.

Carol Hernández Rodríguez. Mexicana. Doctora en Sociología por la Universidad Estatal de Portland, Estados Unidos. Se encuentra adscrita al Departamento de Sociología de la misma universidad. Su especialidad es el manejo y conservación de la agrobiodiversidad a nivel comunitario y desarrolla actualmente el proyecto "El movimiento de soberanía de las semillas y manejo y conservación de la agrobiodiversidad en el contexto de cambio climático”.

hcarol@pdx.edu

Hugo Perales Rivera. Mexicano. Doctor en Ecología por la Universidad de California en Davis, Estados Unidos. Se encuentra adscrito a El Colegio de la Frontera Sur, San Cristóbal de Las Casas, Chiapas, México. Su especialidad es la evolución y adaptación de las variedades de maíz y su proyecto en curso se titula "Adaptación local de variedades tradicionales de maíz en Chiapas, cambio y resiliencia de la producción de maíz en México”. Entre sus publicaciones más recientes se encuentran "Agricultural Change and Resilience: Agricultural Policy, Climate Trends and Market Integration in the Mexican Maize System", "Evolutionary and Food Supply Implications of Ongoing Maize Domestication by Mexican Campesinos" y "Structure of Local Adaptation Across the Landscape: Flowering Time and Fitness in Mexican Maize (Zea mays L. subsp. Mays) Landraces", todas en coautoría.

hperales@ecosur.mx 
Daniel Jaffee. Estadounidense. Doctor en Recursos de la Tierra por el Instituto Nelson de Estudios Ambientales de la Universidad de Wisconsin, Madison, Estados Unidos. Se encuentra adscrito al Departamento de Sociología de la Universidad Estatal de Portland, Estados Unidos. Sus especialidades son el comercio justo y el manejo del agua y su proyecto de investigación se titula "Conflictos por el manejo de agua en México, Estados Unidos y Canadá". Entre sus publicaciones más recientes se encuentran "Draining Us Dry: Scarcity Discourses in Contention over Bottled Water Extraction", "Fair Trade" y "Who's the Fairest of Them All? The Fractured Landscape of U.S. Fair Trade Certification", todas en coautoría.

jaffee@pdx.edu 